\title{
Biossegurança e a prática baseada em evidências
}

\author{
Biosafety and evidence-based practice
}

A prática baseada em evidências observa as melhores evidências científicas disponíveis na literatura em saúde e utiliza os conceitos de eficiência, qualidade e segurança como pilares da decisão a ser tomada pelo profissional de saúde ao realizar um julgamento clínico e/ou epidemiológico, seja esse referente a uma intervenção terapêutica, diagnóstica ou preventiva'. A biossegurança, entre todas as suas definições e significados, encontra em seu escopo o desafio de questionar o quanto medidas preventivas, práticas de contenção e de mitigação do agente biológico estão efetivamente comprovadas e baseadas em evidências².

O questionamento da realidade faz parte do princípio científico e da natureza humana. Foi assim, na segunda metade do século XIX, que o médico húngaro Ignaz Phillipp Semmelweis, em suas observações, evidenciou que a prática da lavagem das mãos e o uso de antissépticos eram fundamentais na prevenção da infecção cruzada e da febre puerperal ${ }^{3}$. Seu achado contribuiu para a valorização de práticas preventivas no controle de infecções em serviços de saúde e também em biossegurança. No entanto, somente postumamente conquistou o reconhecimento de seu postulado, pois, em vida, suas evidências foram arduamente questionadas pelos seus pares e sua posição desmerecida.

Hoje, é bem razoável e reconfortante saber que o conhecimento e as evidências científicas são mais acessíveis e menos questionáveis em relação a sua aplicabilidade, substituindo, muitas vezes, a opinião do especialista, ou ainda, práticas não confirmadas em método e resultado. Por isso, no cenário atual dos serviços de saúde, praticamente não se utilizam protocolos, medicamentos, meios diagnósticos ou outras tecnologias em saúde que não sejam baseadas em revisões sistemáticas ou em estudos bem controlados. Os guidelines e os protocolos se tornaram os amigos mais fiéis do profissional de saúde em sua prática diária. Todavia, apoiando-se em uma das passagens do pensador grego Heráclito de Éfeso (540-470 a.C.), nada existe em caráter permanente, a não ser a mudança; e, por esse prisma, é possível também reconhecer que a ciência e a prática em saúde evolvem, e, com elas, novos questionamentos e paradigmas se formam.

No vasto cenário dos agentes biológicos, pode-se dizer que existe um mundo de possibilidades. Eventos globais retratam doenças emergentes e reemergentes com importância em saúde pública. SARS, Influenza A, Ebola, Chikungunya, MERS-CoV e vírus Zika chamam a atenção de especialistas pelas características atribuídas, como patogenicidade, virulência, viabilidade no meio ambiente e transmissão para a populaçã $0^{4,5,6}$. Os olhares para o mundo das bactérias encontram lentes aumentadas de preocupação quando se trata da resistência bacteriana envolvendo as Superbugs: superbactérias com expressão de genes de resistência para além dos limites normais de resposta aos antibióticos usuais e disponíveis ${ }^{7}$. Da mesma forma, a expectativa sobre o uso do Anthrax em ações de bioterrorismo é real, levando a se observar, com cautela, as pesquisas com agentes biológicos com dupla finalidade ou finalidade duvidosa. Além disso, o risco em relação ao uso indevido de agentes biológicos manipulados geneticamente também é alvo de inquietação por parte de pesquisadores e instituições governamentais de regulação e controle ${ }^{8,9}$. Nesse sentido, a produção de conhecimento sobre esses agentes reforça, muitas vezes, sua condição de risco e, com isso, a necessidade de incorporação de novas medidas de mitigação e controle e novos modelos de atuação em biossegurança. Um estudo realizado em 1995 pelo Instituto de Pesquisa de Doenças Infecciosas do Exército norte-americano, em Frederick, estado de Maryland, demostrou a possibilidade de aerossolização do vírus Ebola em um experimento controlado com animais infectados ${ }^{10}$. Até então, essa condição não fazia parte da natureza de disseminação desse agente.

Além da questão natural, existe ainda a preocupação relacionada às condições de manipulação de agentes biológicos. Estudos sobre o uso de barreiras e métodos de contenção de agentes devem ser estimulados. Sulkin ${ }^{11}$, no início dos anos 60 do século passado, já demonstrou que as infecções adquiridas em laboratórios são de difícil confirmação, pois os mecanismos de transmissão de agentes biológicos nesses ambientes não ocorrem necessariamente por vias naturais, e, com isso, a exposição é de difícil caracterização.

De uma forma geral, os profissionais de saúde, quando expostos a agentes biológicos, podem também se infectar e desenvolver um curso subclínico da doença, tornando a vigilância comprometida sem o uso de baselines sorológicos, seja no contexto de laboratório ou no contexto hospitalar.

Assim, mediante uma variedade de perguntas sem respostas sobre as características e a dinâmica dos agentes biológicos e os riscos eminentes a eles atribuídos, novas práticas podem ser incorporadas no dia a dia, sem que haja evidências suficientes para sustentá-las, ao ponto que outras práticas podem acabar sendo preservadas por anos e anos sem que estudos, bem desenhados e controlados, sejam realizados para se confirmar com suficiência a sua manutenção. $O$ uso de protetores de sapatos frequentemente pode ser citado como um caso não resolvido, 
pois não se encontram evidências sustentáveis que eles determinem uma proteção efetiva do profissional ou de um ambiente frente à contaminação biológica ${ }^{12}$.

Por outro lado, mesmo sem estudos prévios, algumas práticas acabam sendo muito bem aceitas em sua introdução quando valorizam o princípio da redundância, como o caso da paramentação supervisionada e da higienização de mãos enluvadas como medida de prevenção de contaminação pelo vírus Ebola na epidemia de 2014. No entanto, modelos adaptados e baseados em dados insuficientes não favorecem uma intervenção efetivamente segura, pois não foram estruturados e/ou testados de forma a contextualizar sua eficiência diante da magnitude do problema, ou seja, uma situação real de risco e, dessa forma, não são suficientes para respondê-lo.

Por fim, a evolução do conhecimento sobre as doenças emergentes e reemergentes sempre despertará a atenção para novos questionamentos e argumentos na biossegurança. Nesse ponto de entendimento, a biossegurança baseada em evidências deve ser utilizada tanto para sustentar uma ação já conhecida, para construir novos modelos de atuação, como, também, para simplesmente modificar hábitos. Por isso, sustenta-se que a biossegurança baseada em evidências deva extrapolar os protocolos e ser incorporada no comportamento do profissional, moldando hábitos individuais e inserindo-se na cultura institucional. Talvez, com isso, Semmelweis pudesse compreender hoje o porquê da lavagem das mãos ser ainda amplamente divulgada e promovida entre serviços e profissionais de saúde, apesar da sua obviedade secular ${ }^{13}$. Voltar-se para sua história é reconfirmar que o valor da evidência científica em saúde não está atrelado a sua existência em si, mas sim a sua razão de ser, a sua verdadeira aplicabilidade.

\author{
Fernando Henrique Brandão Molento \\ Instituto Evandro Chagas/SVS/MS, Biossegurança, \\ Ananindeua, Pará, Brasil \\ Editor Associado da RPAS, Instituto Evandro \\ Chagas/SVS/MS, Ananindeua, Pará, Brasil
}

\title{
REFERÊNCIAS
}

1 Brettle A. Systematic reviews and evidence based library and information practice. Evid Based Libr Inf Pract. $2009 ; 4(1): 43-50$.

2 Kimman TG, Smit E, Klein MR. Evidence-based biosafety: a review of the principles and effectiveness of microbiological containment measures. Clin Microbiol Rev. 2008 Jul;21 (3):403-25.

3 Martínez O. La ofensiva de Ignaz Semmelweis contra los miasmas ineluctables y el nihilismo terapéutico. Acta Med Colomb. 2014 ene-mar;39(1):90-6.

4 Marshall C, Kelso A, McBryde E, Barr IG, Eisen DP, Sasadeusz J, et al. Pandemic (H1N1) 2009 risk for frontline health care workers. Emerg Infect Dis. 2011 Jun;17(6):1000-6.

5 Zumla A, Alagaili AN, Cotten M, Azhar El. Infectious diseases epidemic threats and mass gatherings: refocusing global attention on the continuing spread of the Middle East respiratory syndrome coronavirus (MERS-CoV). BMC Med. 2016 Sep;14(1):132.

6 Saiz JC, Vázquez-Calvo A, Blázquez AB, Merino-Ramos T, Escribano-Romero E, Martín-Acebes MA. Zika virus: the latest newcomer. Front Microbiol. 2016 Apr;7:496.

7 Khan SN, Khan AU. Breaking the spell: combating multidrug resistant "superbugs". Front Microbiol. 2016 Feb;7:174.

8 Gayathri D, Eramma NK, Devaraja TN. New Delhi metallo beta- lactamase-1; incidence and threats. Int J Biol Med Res. 2012;3(2):1870-4.

9 Berns Kl. Grand challenges for biosafety and biosecurity. Front Bioeng Biotechnol. 2014 Sep;2:35.

10 Johnson E, Jaax N, White J, Jahrling P. Lethal experimental infections of rhesus monkeys by aerosolized Ebola virus. Int J Exp Pathol. 1995 Aug;76(4):227-36.

11 Sulkin SE. Laboratory-acquired infections. Bacteriol Rev. 1961 Sep;25(3):203-9.

12 Hickman-Davis JM, Nicolaus ML, Petty JM, Harrison DM, Bergdall VK. Effectiveness of shoe covers for bioexclusion within an animal facility. J Am Assoc Lab Anim Sci. 2012 Mar;51 (2):181-8.

13 World Health Organization. Guideline on hand hygiene in health care in the context of filovirus disease outbreak response: rapid advice guideline. Geneva: WHO; 2014. 12 p. 